\title{
Attitudes of the public to arthritis
}

\author{
ELIZABETH M. BADLEY AND PHILIP H. N. WOOD
}

From the Arthritis and Rheumatism Council Epidemiology Research Unit, University of Manchester

SUMMARY A survey of the public's attitude to arthritis was commissioned by the Arthritis and Rheumatism Council (ARC) in 1974. The survey was carried out by National Opinion Polls (NOP) Market Research Ltd. The ARC were interested to find out whether people underestimated arthritis and what they thought about the consequences. Respondents were asked to rank a number of illnesses in terms of their seriousness and the loss of work to which they give rise. They were also shown a series of statements about arthritis and rheumatism in order to elicit the extent of their agreement with the views these represented. The public appear to have fairly realistic ideas about the magnitude of the problem and of its nature and associations. However, although the pain of arthritis and rheumatism was appreciated, their possible impact in terms of disturbance of the normal pattern of daily life tended to be underestimated. The findings reflect the climate of opinion from which present and potential arthritis sufferers come and may therefore reveal part of their attitudes to their disease.

It is understandable that an organisation dependent upon voluntary contribution should be interested in the public's estimation of its mission and of the seriousness and consequences of the diseases to which this mission relates. Hence the commissioning by the Arthritis and Rheumatism Council (ARC) of a survey of public attitudes to arthritis. This was carried out by National Opinion Polls (NOP) Market Research Ltd. The report on the survey has been made available to us, and we have examined some of the findings in greater detail. We believe that the results are of interest to a wider audience, and particularly to those who encounter arthritis sufferers in their working life. By providing some insight into general knowledge and awareness the findings reflect the climate of opinion from which present and potential arthritis sufferers come and reveal a part of their attitudes to their disease.

\section{Methods}

A quota sample was used, chosen so as to reflect the sex, age, and social class of the general population, and in addition to give an equal number of interviews in 4 types of area, namely, heavily industrialised, large urban, smaller urban, and rural. The questionnaire covered certain personal details

Accepted for publication 23 April 1978

Correspondence to Dr E. M. Badley, ARC Epidemiology Research Unit, Stopford Building (University of Manchester), Oxford Road, Manchester M13 9PT. of the respondents such as age, social class, working status, and region of residence. Respondents were asked whether they suffered from arthritis and, if so, how badly and how often. A similar inquiry was made about relatives or friends with arthritis. Respondents were asked to rank a list of illnesses in order of lost working days caused and a similar list in terms of the seriousness of the conditions. Respondents were also shown a list of statements about arthritis and rheumatism with which they could agree or disagree either slightly or strongly, or neither agree nor disagree. It should be noted that the words arthritis and rheumatism were used as general terms in the questionnaire, with no attempt at diagnostic specificity.

The interviews were carried out in March 1974 in selected locations in England, Wales, and Scotland, and 503 persons aged 16 and over were interviewed in their own homes. Eighty-two (16\%) of them said that they suffered from arthritis themselves, and a further $200(40 \%)$ said that they had a relative or a friend who suffered. We have called the latter the 'aware', as it might be expected that they would be more sensitive to the difficulties and problems created by arthritis. The remainder of the sample $(44 \%)$ had had no contact with arthritis.

\section{Results}

In general terms those questioned appeared to have a reasonable appreciation of arthritis and rheumatism 
as one of the major causes of lost working days. In comparison with other conditions it was thought to be less serious than heart disease and kidney disease, and more serious than bronchitis or migraine. Respondents were almost unanimously in favour of supporting research into arthritis and rheumatism. Statements made about other aspects of arthritis are summarised in Table 1.

\section{CHARACTERISTICS OF ARTHRITIS}

On the whole arthritis was not thought either to be fatal or to leave the sufferer completely helpless, though overall about a quarter of respondents were not certain. There was a marked age difference in response; more older respondents agreed with the nonfatal nature, but they tended to be less sure that the sufferer was not left completely helpless. Understandably sufferers had more realistic views of the situation than nonsufferers.

\section{POTENTIAL FOR CHANGE}

The feeling that arthritis always gets worse and never better was quite common, especially among the older respondents, though about a fifth were un- $\square$ certain. There was also fair agreement that there is? no known cure. This was particularly thought to be the case by sufferers and by the elderly. In contrast? to this generally pessimistic outlook, however, the great majority of respondents agreed to the statement that medical treatment can help relieve arthritis.

\section{CAUSES AND PREDISPOSITION}

A majority agreed that nobody understands what causes arthritis and that it is not another part of growing old, though older respondents did seem moreo ready to accept arthritis as a normal part of the aging process. Various statements reflecting what are ${ }_{\infty}^{\omega}$ commonly thought to be traditional beliefs about predisposition to arthritis were rejected. Most $\because$ people did not accept the statements that you nevero suffer from arthritis if you remain active, that sufferers get arthritis only in cold weather, and that $>$ arthritis affects only people in damp climates. However, there was more uncertainty about the $\vec{\theta}$ link between arthritis and cold climates, and, inç

Table 1 Response to statements about arthritis by the whole sample and by selected subgroups

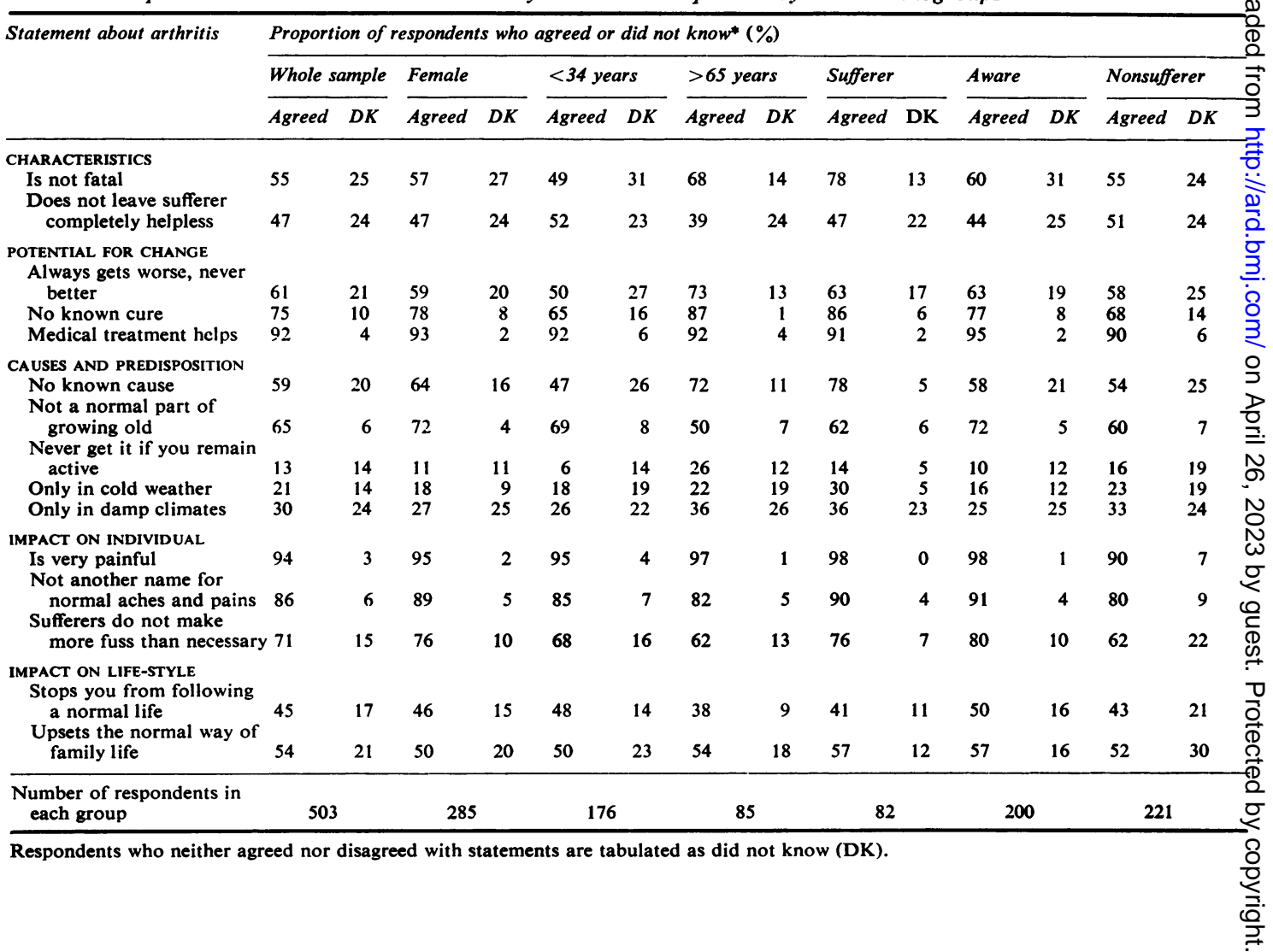


particular, sufferers and the elderly were more inclined to agree that there was an association. In response to another question it was generally acknowledged that arthritis attacks the sufferer all the year round and not only in the winter.

\section{IMPACT ON THE INDIVIDUAL}

People were virtually unanimous that arthritis is a very painful condition and that arthritis is not usually only another name for normal aches and pains. Most also agreed that sufferers do not make more fuss about arthritis than is necessary. Sufferers and the aware tended to be more sure about the latter question, although, somewhat surprisingly, the elderly were less inclined to subscribe to this view.

\section{IMPACT ON THE FAMILY}

There was some degree of uncertainty in response to statements about the impact of arthritis on the way of life of the sufferer and his family. On balance there were more people who agreed than disagreed that arthritis stops you from following a normal life, but the margin was narrow. Paradoxically, although almost half the sufferers thought that arthritis did not stop you from following a normal life, only just over a third of the aware and nonsufferers held this view. On the whole it was thought that arthritis upsets the normal way of family life, though people were not too sure about this.

\section{EFFECT OF KNOWLEDGE OF ARTHRITIS}

In terms of their attitude to arthritis and the degree of suffering it causes it might be expected that the aware would occupy a position intermediate between sufferers and those with no contact with the disease. This was by no means consistently the case, as can be seen by inspection of the appropriate

Table 2 Views of sufferers and the aware on the extent of suffering from arthritis

\begin{tabular}{|c|c|c|}
\hline \multirow[t]{2}{*}{ Extent of suffering } & \multicolumn{2}{|c|}{ Proportion of sufferers who suffer (\%) } \\
\hline & Sufferers & The aware* \\
\hline $\begin{array}{l}\text { FREQUENCY } \\
\text { Constantly } \\
\text { Occasionally }\end{array}$ & $\begin{array}{l}51 \\
48\end{array}$ & $\begin{array}{l}77 \\
20\end{array}$ \\
\hline $\begin{array}{l}\text { DEGREE } \\
\text { Badly } \\
\text { Slightly } \\
\text { Varies, both badly and } \\
\text { slightly }\end{array}$ & $\begin{array}{l}26 \\
46 \\
\\
29\end{array}$ & $\begin{array}{l}71 \\
10 \\
16\end{array}$ \\
\hline Number of respondents & 82 & 111 \\
\hline
\end{tabular}

* The data refer to friends of the aware, as similar information on suffering relatives was not available. columns in Table 1. Sufferers and the aware were also asked about the extent of suffering by themselves and their friends respectively (Table 2). Unfortunately the data on the aware with a suffering relative were not given in the report. More of the aware claimed that their friend suffered constantly and badly than the sufferers recorded about their own suffering (Table 2).

\section{Discussion}

From this survey it seems that the public have a fairly realistic idea about the magnitude of the problem of arthritis and of its nature and associations. It is somewhat surprising, though, how little credence was given to the popular explanations for arthritis in terms of climatic factors. On the whole there was fairly widespread uncertainty about the outcome of arthritis, both in terms of its possible fatal nature and also its ability to cripple. This could be in part due to the generality of the term arthritis as used in the questionnaire. Although it was acknowledged that the condition was very painful, people seemed to have some difficulty associating this with the possible impact in terms of disturbance of the normal pattern of daily life.

The group we have referred to as the aware could be regarded as a more educated group. However, they indicate the need for caution and sensitivity, as they seemed to have a gloomier view of the extent and frequency of suffering from arthritis than did the sufferers themselves. This paradox could be explained were it true that those claiming to have arthritis in fact suffered from a milder form than that afflicting the friends of the aware; unfortunately we have no data on this point. One implication, however, is that this group of nonsufferers may well be likely to be much more fearful of the consequences if they should themselves begin to experience joint pain. This would suggest the need to make special efforts clinically to identify and reassure this group of patients when they present for the first time.

The basic purpose of the study was to learn more of what might be needed to encourage the public to support research in this field. In its public relations activities the Arthritis and Rheumatism Council has always been concerned more to disseminate general information on the rheumatic diseases than to concentrate on the council's efforts to promote research on these conditions. The fairly realistic appreciation of the size of the problem revealed by this study is therefore encouraging. Nothing comparable to this survey has been undertaken before, so that it is difficult to evaluate the impact of previous efforts at publicity. Nevertheless, those concerned with public 
attitudes have the impression that people are better informed than they were some years ago, and the sustained growth in support for ARC (Wood, 1977) would appear to encourage this view. If further progress is to be made, the present findings would indicate that general education of the public needs to be augmented so that the potential of arthritis to disrupt family relationships and interefere with other aspects of the normal pattern of daily life is better understood.

\section{Reference}

Wood, P. H. N. (1977). The Way Ahead. A report on research achievements and the challenge for the future. Arthritis and Rheumatism Council and British League Against Rheumatism: London. 